\title{
Review
}

\section{Compartmentalized Regulations of Ion Channels in the Heart}

\author{
Junko KUROKAWA \\ Department of Bio-Informational Pharmacology, Medical Research Institute, Tokyo Medical and Dental \\ University; 2-3-10 Kandasurugadai, Chiyoda-ku, Tokyo 101-0062, Japan.
} Received July 24, 2007

\begin{abstract}
The rate and force of contraction of the heart are precisely controlled by compartmentalized regulation of cardiac ion channels which determine electrical activities. It is known that modulation of cardiac ion channels, which is caused by drug administration, sympathetic nervous system stimulation and gender difference, can increase risks of lethal arrhythmias in carriers of inherited disease mutations. These modulations are thought to also be involved in common cardiac arrhythmias. Because many signaling molecules are localized within single cells, an understanding of the molecular basis of compartmentalized regulation of cardiac channels is a key for understanding and treating the lethal arrhythmias. In this review, I will discuss molecular mechanisms of compartmentalized regulation of cardiac ion channels via drugs, cAMP and sex hormones.
\end{abstract}

Key words ion channel; heart; compartmentalized regulation; drug; cAMP; hormone

\section{INTRODUCTION}

Cardiac electrical activity is generated by the summation of currents through multiple ion channels. The rate and force of contraction of the heart are precisely controlled by compartmentalized regulation of cardiac ion channels which determine the electrical activity. The ventricular action potential is characterized by a long-lasting so-called "plateau" period in which a balance is maintained fairly between small inward and outward currents. Small changes in this balance can have severe functional consequences, mostly in the cardiac repolarization process. Molecular identification of ion channels during the past twenty years has taught us not only complex of electrical formation but also specific targets for pharmacological intervention.

In the last decade, the study of the genetic bases of inherited arrhythmogenetic diseases has achieved several milestones. Several genetic substrates of arrhythmias have been identified, and the functional characterization of mutant proteins has opened new perspectives about the possibility of performing gene-specific therapy. The genetic substrate of arrhythmia is surely a major risk factor (genetic factor), but there are other risk factors triggered mainly by regulation of cardiac ion channels (regulatory factors) (Fig. 1). It is known that modulation of cardiac ion channels, which is caused by drug administration, sympathetic nervous system stimulation and gender difference can increase risks of lethal arrhythmias in carriers of inherited disease mutations. These modulations are thought to also be involved in common cardiac arrhythmias. Because many signaling molecules are localized within single cells, an understanding of the molecular basis of compartmentalized regulation of cardiac channels is a key for understanding and treating the lethal arrhythmias.

In terms of the compartmentalized regulation of cardiac ion channels, this review concerns drug access through the cell membrane, and receptor-mediated signaling by neurotransmitters and hormones based on my previous and recent data. In this review, I will introduce our research on molecular mechanisms of compartmentalized regulation of cardiac ion channels via drugs, cAMP and sex hormones that are summarized as a schematic diagram of cardiac ventricular myocytes (Fig. 2).
LOCALIZED ACCESS TO THE 1,5-BENZOTHIAZEPINE SITE OF THE L-TYPE CA ${ }^{2+}$ CHANNEL

The L-type $\mathrm{Ca}^{2+}$ channels are heteromultimeric proteins consisting of $\alpha 1, \beta 2, \alpha 2 / \delta$, and $\gamma$ subunits. ${ }^{1)}$ The $\alpha 1$ sub-

\section{Study on arrhythmic triggering factors}

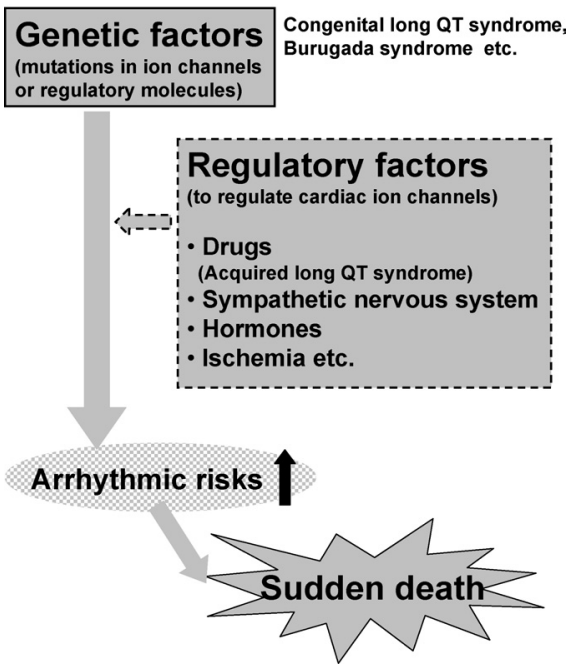

Fig. 1. Scheme for Studies on Arrhythmic Triggering Factors

Compartmentalized regulation of cardiac ion channels

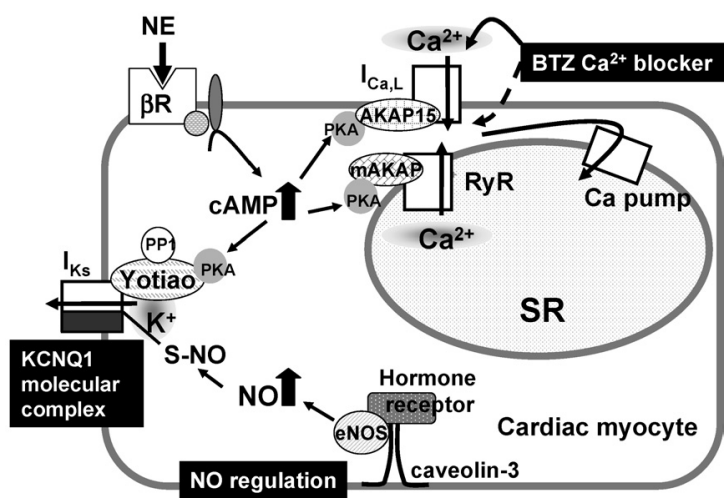

Fig. 2. Schematic Diagram of Compartmentalized Regulation of Cardiac Ion Channels in the Heart 


\section{Phenylalkylamines}
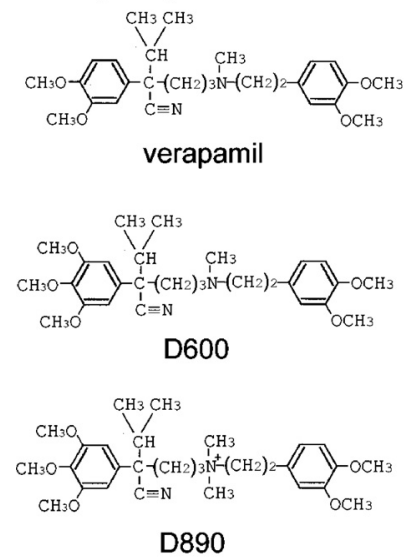

D890

\section{1,5-Benzothiazepines}

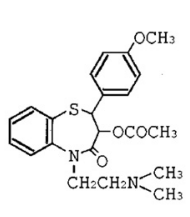

Diltiazem

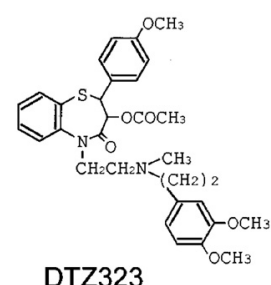

DTZ323
1,4-Dihydropyridines

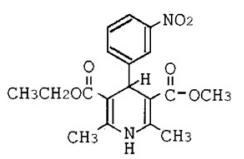

nitrendipine

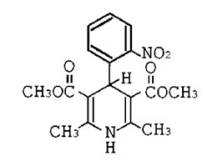

nifedipine
Fig. 3. Chemical Structures of Representative Phenylalkylamines, 1,4-Dihydropyridine, and 1,5-Benzothiazepine Organic $\mathrm{Ca}^{2+}$ Channel Blockers

D890 and DTZ417 are quaternary ammonium derivatives of D600 and DTZ323, respectively.

unit $^{2)}$ contains the binding sites for the three major classes of organic $\mathrm{Ca}^{2+}$ channel modulators (phenylalkylamines; PAA, 1,4-dihydropyridines; DHP, and 1,5-benzothiazepines; BTZ, Fig. 3). Members of these structurally unrelated clinically useful classes of drugs have been invaluable in defining $\mathrm{Ca}^{2+}$ channels and their physiological significance., As therapeutic agents, they have proven effective in the management of cardiac arrhythmias and coronary disease.

Blockade of the L-type $\mathrm{Ca}^{2+}$ channel by the three classes of $\mathrm{Ca}^{2+}$ channel blockers represents a marked difference in degree of tonic block which persists after a long rest or at very slow pulsing from negative potentials. ${ }^{5,6)}$ In 1983 , Lee and $\mathrm{Tsien}^{5)}$ reported systematic comparisons between electrophysiological actions of the three major classes of $\mathrm{Ca}^{2+}$ channel blockers. They found that DHP (Nitrendipine) shows a considerably large degree of tonic block, and BTZ (Diltiazem) also shows a somewhat large degree, whereas tonic block by PAA (D600) is minimal. In turn, the three major class compounds show quantitative differences in the extent to which they display use-dependence (PAA $>$ BTZ $>$ DHP). This is reminiscent of differences between tertiary amine local anesthetics and uncharged local anesthetics in the usedependence of their blockade of $\mathrm{Na}^{+}$channels. ${ }^{6)}$ Thus, this difference in blocking properties may help to explain why PAA is more effective in the heart than DHP at doses equally effective on vascular smooth muscle, and why PAA action is strongly dependent on pacing rate.

On the other hand, in the early 1990s, radioligand binding assay and photoaffinity labeling revealed that the three major types of $\mathrm{Ca}^{2+}$ channel modulators bind to distinct, but allosterically interacting, high affinity binding sites on the $\alpha 1$

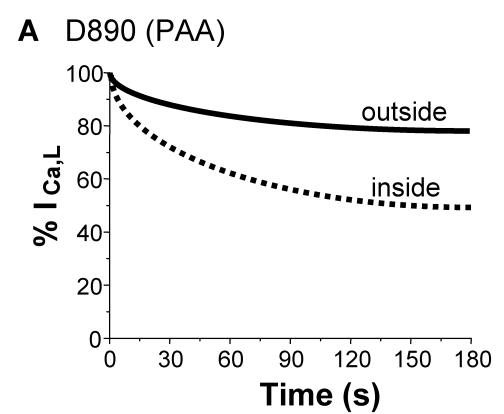

B SDZ-207-180 (DHP)

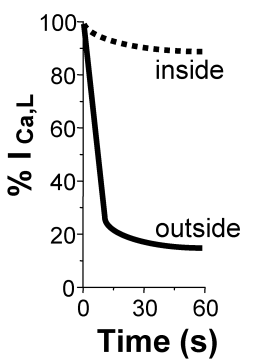

C DTZ417 (BTZ)

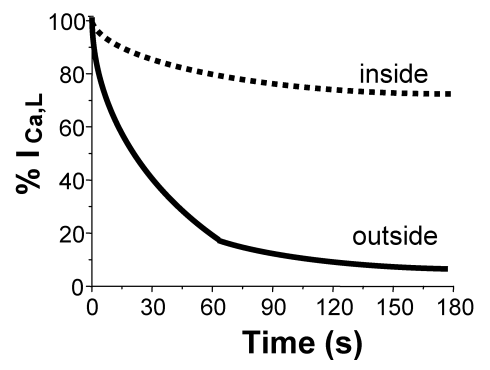

Fig. 4. Relative Effectiveness of External and Internal Quaternary $\mathrm{Ca}^{2+}$ Blockers in Suppressing $\mathrm{I}_{\mathrm{Ca}, \mathrm{L}}$ of Guinea Pig Ventricular Myocytes

Onset of $\mathrm{I}_{\mathrm{Ca}, \mathrm{L}}$ inhibition by the permanently charged $\mathrm{Ca}^{2+}$ blockers was initiated at time 0 by changing the holding potential from $-90 \sim-80 \mathrm{mV}$ to $-40 \mathrm{mV}$. (A) Access of PAA from inside. D890 $(100 \mu \mathrm{M})$ was applied from the external side (solid line) and the internal side (dashed line) ${ }^{8)}$ (B) Access of DHP from outside. External $(0.2 \mu \mathrm{M}$, solid line) and internal ( $1 \mu \mathrm{M}$, dashed line) SDZ-207-180 were applied for 3- and 23min, respectively, before onset of block-enhancing pulses from $-40 \mathrm{mV}^{9)}(\mathrm{C})$. Access of BTZ from outside. DTZ417 $(50 \mu \mathrm{M})$ was applied from the external side (solid line) and the internal side (dashed line). ${ }^{16)}$

subunit of the L-type $\mathrm{Ca}^{2+}$ channels. ${ }^{1,7)}$ Since that time, functional determination has been awaited for the validity of the binding sites predicted by photoaffinity labeling and chimeric channel experiments. Permanently charged derivatives of organic $\mathrm{Ca}^{2+}$ channel blockers (Fig. 3), which are considered to be impermeable through the cell membrane, have been introduced to determine the transmembrane sideness of drug access to block the $\mathrm{Ca}^{2+}$ channel currents $\left(\mathrm{I}_{\mathrm{Ca}, \mathrm{L}}\right)$ by using the whole-cell patch-clamp technique. These studies indicate that the access of PAA to block $\mathrm{I}_{\mathrm{Ca}, \mathrm{L}}$ is localized on the intracellular side of the membrane, ${ }^{8)}$ whereas the access of DHP is from the extracellular side ${ }^{9)}$ (Figs. 4A, B). The limited access of charged PAA from inside seems to fit well with strong frequency-dependence of PAA action.

The story for BTZ is more complex. BTZ and PAA interaction with the channel is somewhat similar in many respects; BTZs and PAAs contain a basic nitrogen essential for activity and, unlike for DHPs, $\mathrm{Ca}^{2+}$ channel block critically depends on frequency of depolarization, although there are quantitative differences. But the discrimination between BTA and PAA is important not only for understanding distinct pharmacological actions but also for prediction of diverse side effects. Although the unique tissue selectivity of diltiazem $^{10)}$ is explained by the voltage-dependence of its interaction with L-type $\mathrm{Ca}^{2+}$ channels ${ }^{11,12)}$ the structure-activity relationship analysis for BTZ was somewhat delayed mainly due to lack of high affinity ligands for the BTZ site. ${ }^{13)}$ Although the quaternary derivative of diltiazem was equally effective from both sides of the membrane, the experiment requires a very high concentration of drugs $(0.1-1 \mathrm{~mm}),{ }^{14}$ which made us wonder if this is the case. We therefore intro- 
duced a potent $\mathrm{Ca}^{2+}$ channel blocking BTZ called DTZ323 and its quaternary ammonium derivative called DTZ417 $7^{12,15}$ (Fig. 3), and revisited the question on accessibility of BTZ to block the L-type $\mathrm{Ca}^{2+}$ channel. We then found that DTZ417 blocked $\mathrm{I}_{\mathrm{Ca}, \mathrm{L}}$ preferentially from outside of the cell membrane (Fig. 4C). ${ }^{16)}$ The data suggest that the BTZ site is accessible from the extracellular side of the L-type $\mathrm{Ca}^{2+}$ channel. Although PAA and BTZ exhibit a similar mechanism of use-dependent block of L-type $\mathrm{Ca}^{2+}$ channels, namely by inducing slow recovery from inactivation, our study showed the clear difference in drug access between BTZ and PAA.

Emerging from site-directed mutagenesis studies is the consensus view that domains III and IV of the $\alpha 1$ subunit are crucial to modulate L-type $\mathrm{Ca}^{2+}$ channel, ${ }^{17,18)}$ and that it is very likely that multiple residues on the $\alpha 1$ subunit interact in an allosteric manner to cause voltage-dependent modulation of the channel gating. There are some critical residues which are specific to the classes, but some residues of the binding sites overlap each other among the classes. The precise orientation of the drug binding sites has not been clarified because of lack of high resolution structural data. Clearly, structural analysis of the proximal drug binding sites will greatly help to unravel the molecular mechanism for modulation of the L-type $\mathrm{Ca}^{2+}$ channel by $\mathrm{Ca}^{2+}$ blockers in the future.

\section{COMPARTMENTALIZED CAMP SIGNALING BY KCNQ1/KCNE1 MACROMOLECULAR SIGNALING COMPLEX}

The sympathetic nervous system (SNS) controls the force and rate of contraction of the heart. Stimulation of the SNS in response to exercise or emotional stress results in a rapid and dramatic increase in heart rate which, in order to ensure adequate diastolic filling time between beats, is accompanied by a concomitant reduction of the ventricular action potential duration (APD) at the cellular level and the corresponding QT interval of the electrocardiogram (ECG). Dysfunctional regulation of cardiac electrical activity in the face of SNS activity can lead to arrhythmias. ${ }^{19)}$

SNS control of cardiac electrical activity is mediated by the activation of $\beta$-adrenergic receptors ( $\beta$-ARs) that regulate the function of select ion channel proteins via phosphorylation by cAMP-dependent protein kinase A (PKA). Targets of PKA include key channels that are involved in the regulation of cellular $\mathrm{Ca}^{2+}$ ion concentration via modulation of the amplitude and APD as well as release of calcium ions from the internal calcium store, the sarcoplasmic reticulum (SR). PKA-dependent phosphorylation augments calcium entry on a beat-by-beat basis by modulating the activity of L-type $\mathrm{Ca}^{2+}$ channels. This enhanced calcium entry contributes to APD prolongation by depolarization of the plateau (Fig. 5A) as well as an increase in intracellular $\mathrm{Ca}^{2+}$ available for subsequent uptake by the cardiac SR. PKA phosphorylation also activates the major intracellular calcium release channel on the SR, the type 2 ryanodine receptor $(\mathrm{RyR} 2)^{20)}$ which is responsible for releasing $\mathrm{Ca}^{2+}$ that triggers muscle contraction.

$\mathrm{I}_{\mathrm{Ks}}$, the slowly activating component of the human cardiac delayed rectifier $\mathrm{K}^{+}$current is a major contributor to repolarization of the cardiac action potential (AP). ${ }^{21,22)}$ Moreover, $\mathrm{I}_{\mathrm{Ks}}$ is a dominant determinant of the physiological heart rate-
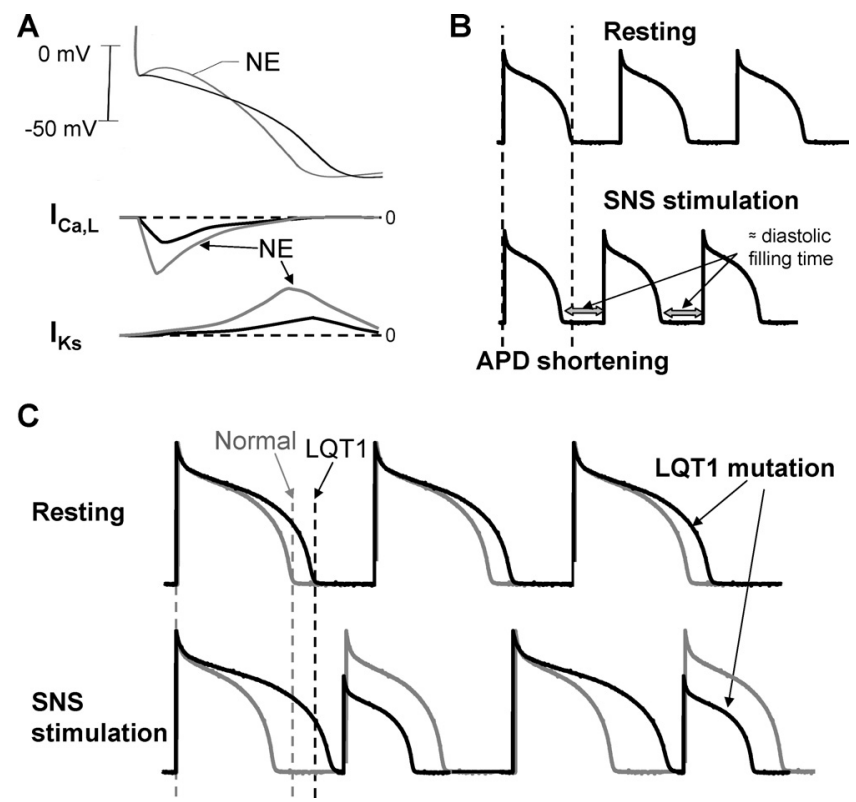

Fig. 5. SNS Regulation of Cardiac Action Potentials

(A) Norepinphrine (NE) increases plateau height and shortens APD in isolated calf Purkinje fibers. ${ }^{24)}$ Lower panels show changes of $\mathrm{I}_{\mathrm{Ca}, \mathrm{L}}$ and $\mathrm{I}_{\mathrm{Ks}}$ during action potential in the presence of NE (SNS stimulation). (B) Schematic diagram of SNS regulation of AP. APD shortening under SNS stimulation (dashed lines) ensures adequate diastolic filling time (arrows). (C) Schematic diagram of influence of LQT-1 mutation on SNS regulation of AP. LQT-1 mutation (loss-of-function) prolongs APD at rest, and ablates the APD shortening response in the face of SNS stimulation. Only upon SNS stimulation are the AP traces altered.

dependent shortening of APD (the rate dependent adaptation of the APD) ${ }^{23)}$ Upon SNS stimulation in response to exercise or emotional stress, the contribution of $\mathrm{I}_{\mathrm{Ks}}$ to the APD shortening is augmented by increased heart rate ${ }^{24)}$ and enhancement of the $\mathrm{I}_{\mathrm{Ks}}$ amplitude ${ }^{25,26)}$ (Fig. 5A). The rapid and dramatic increase in heart rate under SNS stimulation has to be accompanied by the APD shortening in order to ensure adequate diastolic filling time between beats (Fig. 5B). Dysfunction of the $\mathrm{I}_{\mathrm{Ks}}$ channel caused by inherited disease mutation (LQT-1 mutation) causes APD prolongation under basal condition (resting), then, in the face of SNS stimulation, lack of the APD shortening contributed by the $\mathrm{I}_{\mathrm{Ks}}$ channel can increase a risk of arrhythmias dramatically (Fig. 5C). The $\mathrm{I}_{\mathrm{Ks}}$ channel is a major target of PKA phosphorylation that occurs subsequent to $\beta$-AR stimulation. PKA dependent phosphorylation of $\mathrm{I}_{\mathrm{Ks}}$ channels results in increased $\mathrm{I}_{\mathrm{Ks}}$ current amplitude and faster cardiac repolarization ${ }^{25,26)}$ (Fig. 5A). This increase in repolarization currents is essential to counter the stimulatory effects of PKA on L-type $\mathrm{Ca}^{2+}$ channels. $^{24)}$ The result is that a balance of inward and outward membrane currents regulates the duration of ventricular APD, and consequently the QT interval, in response to SNS stimulation.

$\mathrm{I}_{\mathrm{Ks}}$ results from the co-assembly of two subunits, KCNQ1 (KvLQT1) and KCNE1 (minK). ${ }^{27,28)}$ The genes that encode the subunit components of the $\mathrm{I}_{\mathrm{Ks}}$ channel, KCNQ1 and $K C N E 1$ have been shown to harbor mutations linked to the congenital long QT syndrome (LQTS). Mutations in $K C N Q 1$ cause LQT-1, and mutations in KCNE1 cause LQT-529. The familial form of LQTS is predominantly an autosomal dominant disorder associated with recurrent syncope and a propensity to polymorphous ventricular tachycardia (Torsades de pointes) and sudden death. The disease phenotype 
Table 1. Classification of Congenital Long QT Syndrome (LQTS)

\begin{tabular}{cccc}
\hline \hline Classification & \multicolumn{1}{c}{ Gene } & Human locus & Protein \\
\hline \multicolumn{4}{c}{ Romano-Ward syndrome (autosomal dominant form) } \\
LQT1 & $K C N Q 1(K v L Q T 1)$ & $11 \mathrm{p} 15.5$ & $\mathrm{I}_{\mathrm{Ks}}$ channel $\alpha$ subunit \\
LQT2 & $K C N H 2(H E R G)$ & $7 \mathrm{q} 35-\mathrm{q} 36$ & $\mathrm{I}_{\mathrm{Kr}}$ channel $\alpha$ subunit \\
LQT3 & $S C N 5 A$ & $3 \mathrm{p} 21-\mathrm{p} 24$ & $\mathrm{I}_{\mathrm{Na}}$ channel $\alpha$ subunit \\
LQT4 & $A N K B$ & $4 \mathrm{q} 25-\mathrm{q} 27$ & Ankyrin-B \\
LQT5 & $K C N E 1($ minK) & $21 \mathrm{q} 21-\mathrm{q} 22$ & $\mathrm{I}_{\mathrm{Ks}}$ channel $\beta$ subunit \\
LQT6 & $K C N E 2(M i R P 1)$ & $21 \mathrm{q} 21-\mathrm{q} 22$ & $\mathrm{I}_{\mathrm{Kr}}$ channel $\beta$ subunit \\
LQT7 & $K C N J 2$ & $17 \mathrm{q} 23$ & $\mathrm{I}_{\mathrm{K} 1}$ channel $\alpha$ subunit \\
LQT8 & $C A C N A 1 c$ & $12 \mathrm{p} 13.3$ & $\mathrm{I}_{\mathrm{Ca}}$ channel CaV1.2 \\
LQT9 & $C A V 3$ & $3 \mathrm{p} 25$ & $\mathrm{Caveolin}^{2} 3$ \\
LQT10 & $S C N 4 B$ & $11 \mathrm{q} 24$ & $\mathrm{I}_{\mathrm{Na}}$ channel $\beta$ subunit \\
Jervell and Lange-Nielsen syndrome & \\
(autosomal recessive form associated with deafness) \\
JLN1 & $K C N Q 1(K v L Q T 1)$ & $11 \mathrm{p} 15.5$ & $\mathrm{I}_{\mathrm{Ks}}$ channel $\alpha$ subunit \\
JLN2 & $K C N E 1(m i n K)$ & $21 \mathrm{q} 21-\mathrm{q} 22$ & $\mathrm{I}_{\mathrm{Ks}}$ channel $\beta$ subunit \\
\hline
\end{tabular}

a) Adapted from ref. 67.

is caused by inherited defects in the cardiac repolarization process and genetic variants of the disorder have been labeled according to the chronology of linkage of specific genes (Table 1). The functional characterization of mutant proteins in LQTS ${ }^{30-32)}$ has provided profound information of the contribution of specific cardiac ion channels to cardiac repolarization.

In affected LQTS patients, triggers of arrhythmias are gene-specific and those with mutations in either KCNQ1 or KCNE1 are at greatest risk of experiencing a fatal cardiac arrhythmia in the face of elevated SNS activity. ${ }^{33-35)}$ Unraveling the molecular links between the SNS and regulation of the KCNQ1/KCNE1 channel has direct implications for understanding the mechanistic basis of triggers of arrhythmias in LQTS. We discovered that the KCNQ1/KCNE1 channel forms a macromolecular signaling complex that is coordinated by binding of a targeting protein, Yotiao (AKAP9) ${ }^{36}$ ) via a leucine/isoleucine zipper (LIZ) motif in the C-terminus of KCNQ1, which in turn binds to and recruits PKA and PP1 to the channel ${ }^{37)}$ (Fig. 6). The complex then regulates the phosphorylation of $\mathrm{Ser}^{27}$ in the N-terminus of KCNQ1. ${ }^{37}$ The naturally occurring G589D mutation in the LIZ motif disrupts targeting of Yotiao to hKCNQ1 and nullifies $\beta$ adrenergic-mediated regulation of the channel ${ }^{37)}$ (Fig. 6). The inherited G589D mutation has been linked to LQT-1 in Finnish families. $^{38)}$ Affected LQTS patients suffer from dysfunctional regulation of QT duration during mental and physical stress ${ }^{39)}$ and are at risk of arrhythmia and sudden cardiac death during exercise. ${ }^{38)}$

We demonstrated that cAMP-mediated regulation of the $\mathrm{I}_{\mathrm{Ks}}$ channel via PKA phosphorylation of $\mathrm{Ser}^{27)} \mathrm{KCNQ1}$ requires the expression of KCNQ1 with its auxiliary subunit $\mathrm{KCNE} 1$, although KCNE1 is not required for phosphorylation of KCNQ1. ${ }^{26)}$ In other words, KCNQ1 phosphorylation is independent of co-assembly with KCNE1 but transduction of the phosphorylated channel into the physiologically essential increase in reserve channel activity requires the presence of KCNE1. Indeed, a point mutation in KCNE1 linked to LQT-5, D76N, can severely disrupt the functional consequences of KCNQ1 phosphorylation. ${ }^{26)}$ This mutation reduces basal current density and would be expected to reduce repolarizing current, prolong cellular action potentials and

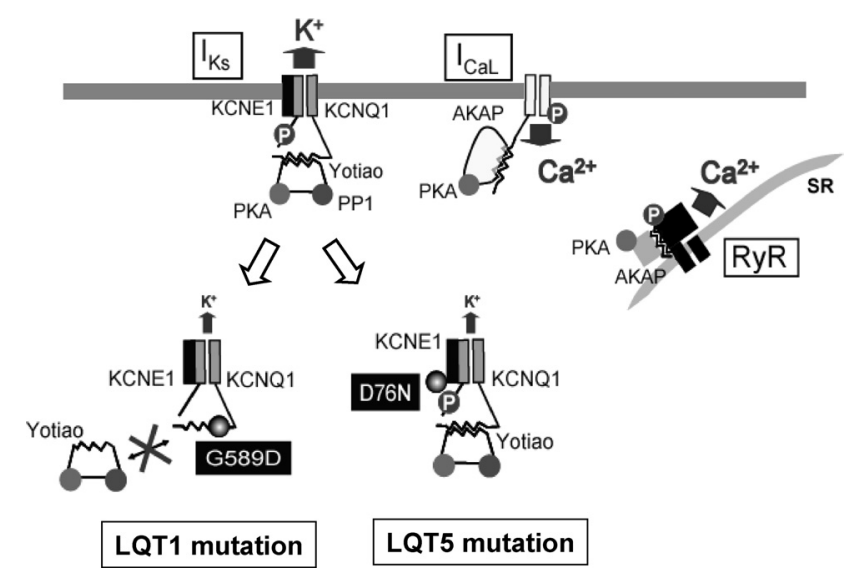

Fig. 6. Disruption of the KCNQ1 Macromolecular Complex by an Inherited Mutation

The targeting protein Yotiao binds to the carboxy terminal domain of KCNQ1 via a LIZ motif (sawtooth in figure) and recruits PKA and PP1 directly to the channel microdomain to regulate the channel via phosphorylation of $\mathrm{Ser}^{27)}$ in the amino terminus (upper panel). ${ }^{37)}$ The $\mathrm{I}_{\mathrm{Ca}, \mathrm{L}}$ channel and RyR2 associate with AKAP15/18 and mAKAP, respectively, via distinct LIZ motifs. ${ }^{66)}$ The LQT-1 mutation G589D occurs in the KCNQ1 LIZ motif and disrupts the $\mathrm{I}_{\mathrm{Ks}}$ signaling complex without changing the $\mathrm{I}_{\mathrm{Ca}, \mathrm{L}}$ or RyR2 signaling complexes. ${ }^{37)}$ The LQT-5 mutation D76N occurs in the KCNE1 cardoxy terminus and ablates transduction of functional consequence of PKA phosphorylation at $\mathrm{Ser}^{27)} \mathrm{KCNQ1}{ }^{26)}$ This ablation is also independent of the $\mathrm{I}_{\mathrm{Ca}, \mathrm{L}}$ and RyR2 signaling complexes.

contribute to prolonged QT intervals in those expressing the mutation even in the absence of SNS stimulation. ${ }^{40)}$ The D76N mutation also ablates functional regulation of the channels by cAMP, ${ }^{26)}$ which can increase the risk of arrhythmia $^{41)}$ (Fig. 6). We recently described direct AKAP-mediated alternation of channel function distinct from its role in the coordination of channel phosphorylation by PKA. ${ }^{42-44)}$ The presumed consequence of the mutation is that in the face of SNS stimulation, there will be an insufficient reserve of $\mathrm{K}^{+}$ channels to allow for appropriate shortening of the APD that is required at faster heart rates to permit the sufficiently long diastolic intervals required for ventricular filling.

Because PKA-dependent regulation of at least three key ion channels in the heart (RyR2, L-type $\mathrm{Ca}^{2+}$ channels, and KCNQ1/KCNE1 channels) requires assembly with AKAPmediated macromolecular signaling complexes, it is clear that disruption of a subset of these complexes can lead to an imbalanced response to SNS stimulation. The LQT-1 mutation, G589D, is the first example of disease-associated disruption of a microdomain-signaling complex. ${ }^{37,45)}$ The D76N mutation of KCNE1 represents a second, and additionally novel, mechanism of disrupting regulation of a local targeted ion channel. ${ }^{26)}$ In the latter case, however, it is functional uncoupling and not biochemical uncoupling that occurs.

\section{NON-GENOMIC REGULATION OF CARDIAC ION CHANNELS BY SEX STEROID HORMONES}

Female sex is an independent risk factor for development of torsade de pointes (TdP) not only in congenital LQTS but also in acquired (drug-induced) LQTS. ${ }^{46,47)}$ Women are more prone to develop TdP than men in response to QT-prolonging drugs, with $65-75 \%$ of the drug-induced TdP occurring in women. ${ }^{46-49)}$ Because drug-induced arrhythmias is the most common reason for withdrawal of medication from drug-development, pre-clinical trials and the retail market, pharma- 
ceutical companies are striving to improve ways to predict the risk of novel agents as early as possible. ${ }^{50)}$ Thus, unraveling the molecular mechanism of the gender difference may be beneficial not only for gender-specific medicines but also for drug-development. The underlying mechanism of the gender difference is still unclear but may be related to longer baseline $\mathrm{QT}_{\mathrm{C}}$ intervals for women than those for men. ${ }^{51)}$

Lower incidence of drug-induced arrhythmias among adult men may be due to shortened QT intervals, more prominent in men than in women after puberty. At birth, the $\mathrm{QT}_{\mathrm{C}}$ interval is quite similar between men and women. ${ }^{52-54)}$ As the sex hormone level elevates during puberty, $\mathrm{QT}_{\mathrm{C}}$ intervals in boys are shortened, leaving adult women with longer $\mathrm{QT}_{\mathrm{C}}$ intervals than adult men. The $\mathrm{QT}_{\mathrm{C}}$ interval in men then gradually increases until the age of $c a$. 60 years when the intervals approach that of women. ${ }^{52-54)}$ The age-dependent gender difference implies that testosterone modifies cardiac ion channel function.

Signaling of gonadal steroids such as testosterone and estrogen has traditionally been identified as transcriptional controls of target genes via binding of complexes of nuclear receptors and ligands to the genomic consensus sequence in reproductive organs (genomic action). ${ }^{55)}$ Although several studies pointed out genomic effects of testosterone, ${ }^{56,57)}$ mechanism of the QT shortenings is still unknown.

Recently, several biological actions of gonadal steroids that are too rapid to be compatible with transcriptional mechanisms have been identified in non-reproductive organs (nongenomic action). ${ }^{58-60)}$ Gender differences in $\mathrm{QT}_{\mathrm{C}}$ intervals have been explained mainly by sex hormone driven differences in gene expression of cardiac ion channels. However, studies on acute/non-genomic effects of testosterone on ionic currents in cardiac myocytes were limited. We therefore examined acute effects of testosterone on APD and membrane currents using patch-clamped guinea pig ventricular myocytes. ${ }^{61)}$ Testosterone rapidly shortened action potential duration (APD) with an $\mathrm{EC}_{50}$ of $c a$. $5 \mathrm{~nm}$ that is within physiological testosterone levels in men. Both enhancement of slowly activating delayed rectifier $\mathrm{K}^{+}$currents $\left(\mathrm{I}_{\mathrm{Ks}}, \mathrm{EC}_{50}\right.$; $c a .1 \mathrm{nM})$ and suppression of L-type $\mathrm{Ca}^{2+}$ currents $\left(\mathrm{I}_{\mathrm{Ca}, \mathrm{L}}, \mathrm{IC}_{50}\right.$; $c a .40 \mathrm{nM}$ ) may contribute to the APD shortening, because the presence of an $\mathrm{I}_{\mathrm{Ks}}$ inhibitor and an $\mathrm{I}_{\mathrm{Ca}, \mathrm{L}}$ inhibitor failed to shorten APD by testosterone. Testosterone did not modify $\mathrm{I}_{\mathrm{Kr}}$ channel currents at these concentrations. Nitric oxide (NO) scavengers and an inhibitor of NO synthase 3 (NOS3) reversed the effects of testosterone on APD and membrane currents, suggesting that $\mathrm{NO}$ released from NOS3 is responsible for the effects of testosterone. These effects were reversed by a blocker of testosterone receptors, a c-Src inhibitor, a PI-3 kinase (PI3K) inhibitor, and an Akt inhibitor, indicating involvement of a receptor-mediated signaling pathway through these kinases. These data suggest that the testosterone-induced modification of $\mathrm{I}_{\mathrm{Ks}}$ and $\mathrm{I}_{\mathrm{Ca}, \mathrm{L}}$ are due to $\mathrm{NO}$ production through a non-genomic pathway, in which c-Src/PI3K/ Akt/NOS3 are sequentially activated (Fig. 7). The non-genomic regulation of these two currents by testosterone is a novel regulatory mechanism of cardiac repolarization. This regulation may contribute at least in part to sex-related differences in $\mathrm{QT}_{\mathrm{C}}$ intervals and susceptibility to drug-induced arrhythmias.

Although the $\mathrm{I}_{\mathrm{Ca}, \mathrm{L}}$ suppression and the $\mathrm{I}_{\mathrm{Ks}}$ enhancement by

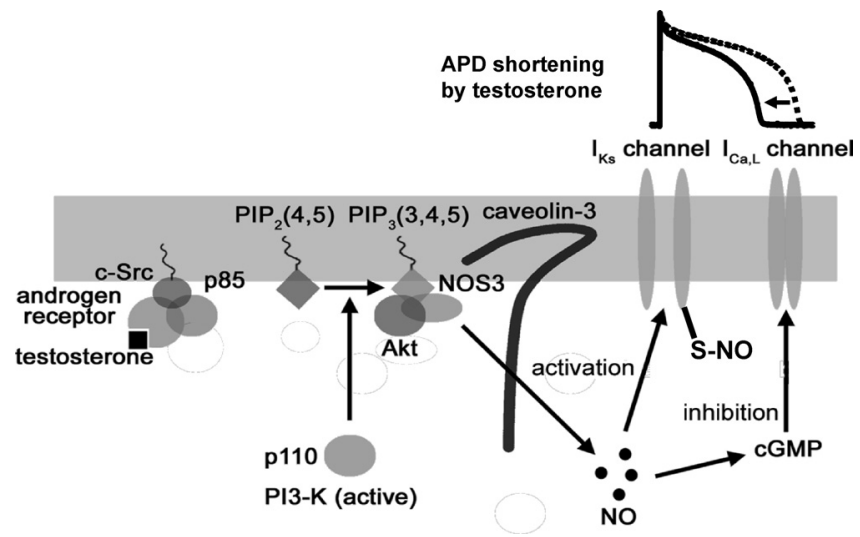

Fig. 7. Schematic Diagram for Regulatory Mechanism of Testosterone on $\mathrm{I}_{\mathrm{Ca}, \mathrm{L}}$ and $\mathrm{I}_{\mathrm{Ks}}$

When testosterone binds to its receptors, testosterone receptor, c-Src, and p85 of PI3kinase form a macro-molecular complex, making p110 of PI3-kinase free and in an active state, and active PI3-kinase converts $\mathrm{PIP}_{2}(4,5)$ to $\operatorname{PIP}_{3}(3,4,5)$. Subsequently, $\mathrm{PIP}_{3}(3,4,5)$, Akt, and NOS3 form a complex, resulting in NOS3 activation and NO production. Produced NO inhibits $\mathrm{I}_{\mathrm{Ca}, \mathrm{L}}$ in a cGMP-dependent manner and enhances $\mathrm{I}_{\mathrm{Ks}}$ in a cGMP-independent manner, and thus APD is shortened. ${ }^{61)}$

testosterone are mediated through NO production via the same non-genomic pathway from activation of $\mathrm{c}-\mathrm{Src}$ to NOS3 activation, the concentrations of testosterone to modulate $\mathrm{I}_{\mathrm{Ca}, \mathrm{L}}$ and $\mathrm{I}_{\mathrm{Ks}}$ differ. This could be explained by differential regulating mechanisms of $\mathrm{NO}$. The suppression of $\mathrm{I}_{\mathrm{Ca}, \mathrm{L}}$ by $\mathrm{NO}$ is dependent on cGMP, while the enhancement of $\mathrm{I}_{\mathrm{Ks}}$ by NO is not dependent on cGMP, suggesting involvement of direct $s$-nitrosylation of channel protein. ${ }^{62)}$ A23187-induced $\left[\mathrm{Ca}^{2+}\right]_{\text {in }}$ increase in guinea pig myocytes modulates $\mathrm{I}_{\mathrm{Ca}, \mathrm{L}}$ and $\mathrm{I}_{\mathrm{Ks}}$ as seen in the regulation by testosterone, and the $\mathrm{Ca}^{2+}$ regulation of the channels is also through NO release through NOS3 activation. ${ }^{63)}$ Although there is evidence of direct $s$-nitrosylation of cardiac $\mathrm{I}_{\mathrm{Ca}, \mathrm{L}}$ channels, ${ }^{64,65)}$ our results indicate differential mechanisms of the NO regulation through NOS3 between the $\mathrm{I}_{\mathrm{Ca}, \mathrm{L}}$ channel and the $\mathrm{I}_{\mathrm{Ks}}$ channel, suggesting a compartmentalized regulation of $\mathrm{I}_{\mathrm{Ca}, \mathrm{L}}$ and $\mathrm{I}_{\mathrm{Ks}}$ by NO. However, the mechanism for the compartmentalization of this NO regulation of cardiac ion channels has not been clarified.

\section{CLOSING REMARKS}

I have here introduced our previous research and recent progress on molecular mechanisms of compartmentalized regulation of cardiac ion channels via the drugs, cAMP and NO. First, local access of the traditional major three class $\mathrm{Ca}^{2+}$ channel blockers was discussed. We previously found that a quaternary derivative of a BTZ $\mathrm{Ca}^{2+}$ blocker (diltiazem-class) blocked $\mathrm{I}_{\mathrm{Ca}, \mathrm{L}}$ preferentially from outside of the cell membrane. Next, compartmentalized regulation of cardiac ion channels upon SNS stimulation was discussed. We found that the $\mathrm{I}_{\mathrm{Ks}}$ channel, a major contributor to cardiac repolarization, forms a macromolecular complex with the targeting protein AKAP9 (Yotiao) to up-regulate the $\mathrm{I}_{\mathrm{Ks}}$ activity upon cAMP-stimulation. The complex is involved in increased risk of fatal arrhythmias in the face of sympathetic nervous system activity. As cardiac ion channels which are PKA substrate interact with distinct AKAPs, Yotiao may contribute compartmentalized cAMP signaling upon SNS stimulation in the heart. Third, modulation of cardiac $\mathrm{I}_{\mathrm{Ks}}$ and $\mathrm{I}_{\mathrm{Ca}, \mathrm{L}}$ by NO-production via a non-genomic action of sex hor- 
mones was discussed. The regulation may have a major impact on sex-related difference in QT intervals and susceptibility to drug-induced arrhythmias. Localized NO regulation of both channels was suggested to be dependent on cGMP.

Acknowledgements I would like to thank Dr. Taku Nagao (Food Safety Commission), Dr. Robert S. Kass (Columbia University) and Dr. Tetsushi Furukawa (Tokyo Medical and Dental University) for their invaluable guidance and suggestions. I also thank all of my teachers, colleagues and collaborators for their support of my research. This work was partly supported by a Grant from the Ministry of Education, Science, Sports, Culture, and Technology of Japan, and grants from the Naito Foundation and Uehara Foundation.

\section{REFERENCES}

1) Catterall W. A., Striessnig J., Trends Pharmacol. Sci., 13, 256-262 (1992).

2) Tanabe T., Takeshima H., Mikami A., Flockerzi V., Takahashi H., Kangawa K., Kojima M., Matsuo H., Hirose T., Numa S., Nature (London), 328, 313-318 (1987).

3) Fleckenstein A., Annu. Rev. Pharmacol. Toxicol., 17, 149-166 (1977).

4) McDonald T. F., Pelzer S., Trautwein W., Pelzer D. J., Physiol. Rev., 74, 365-507 (1994).

5) Lee K. S., Tsien R. W., Nature (London), 302, 790-794 (1983).

6) Uehara A., Hume J. R., J. Gen. Physiol., 85, 621-647 (1985).

7) Glossmann H., Ferry D. R., Goll A., Striessnig J., Zernig G., Arzneim.Forsch., 35, 1917-1935 (1985).

8) Hescheler J., Pelzer D., Trube G., Trautwein W., Pflugers Arch., 393, 287-291 (1982).

9) Kass R. S., Arena J. P., Chin S., J. Gen. Physiol., 98, 63-75 (1991).

10) Nagao T., Narita H., Sato M., Nakajima H., Kiyomoto A., Clin. Exp. Hypertens. A, 4, 285-296 (1982).

11) Okuyama R., Adachi-Akahane S., Nagao T., Br. J. Pharmacol., 113, $451-456$ (1994).

12) Kurokawa J., Adachi-Akahane S., Nagao T., Eur. J. Pharmacol., 325, 229-236 (1997).

13) Narita H., Gaino M., Suzuki T., Kurosawa H., Inoue H., Nagao T., Chem. Pharm. Bull., 38, 407-410 (1990).

14) Adachi-Akahane S., Amano Y., Okuyama R., Nagao T., Jpn. J. Pharmacol., 61, 263-266 (1993).

15) Hagiwara M., Adachi-Akahane S., Nagao T., J. Pharmacol. Exp. Ther, 281, 173-179 (1997).

16) Kurokawa J., Adachi-Akahane S., Nagao T., Mol. Pharmacol., 51, 262-268 (1997).

17) He M., Bodi I., Mikala G., Schwartz A., J. Biol. Chem., 272, 26292633 (1997).

18) Yamaguchi S., Okamura Y., Nagao T., Adachi-Akahane S., J. Biol. Chem., 275, 41504-41511(2000).

19) Wit A. L., Hoffman B. F., Rosen M. R., Am. Heart J., 90, 665-675 (1975).

20) Marx S. O., Reiken S., Hisamatsu Y., Jayaraman T., Burkhoff D., Rosemblit N., Marks A. R., Cell, 101, 365-376 (2000).

21) Clancy C. E., Kurokawa J., Tateyama M., Wehrens X. H., Kass R. S., Annu. Rev. Pharmacol. Toxicol., 43, 441-461 (2003).

22) Kurokawa J., Abriel H., Kass R. S., J. Mol. Cell. Cardiol., 33, 873 882 (2001).

23) Zeng J., Laurita K. R., Rosenbaum D. S., Rudy Y., Circ. Res., 77 $140-152$ (1995).

24) Kass R. S., Wiegers S. E., J. Physiol., 322, 541-558 (1982).

25) Walsh K. B., Kass R. S., Science, 242, 67-69 (1988).

26) Kurokawa J., Chen L., Kass R. S., Proc. Natl. Acad. Sci. U.S.A., 100 2122-2127 (2003).

27) Sanguinetti M. C., Curran M. E., Zou A., Shen J., Spector P. S., Atkinson D. L., Keating M. T., Nature (London), 384, 80-83 (1996).

28) Barhanin J., Lesage F., Guillemare E., Fink M., Lazdunski M., Romey G., Nature (London), 384, 78-80 (1996).

29) Splawski I., Shen J., Timothy K. W., Lehmann M. H., Priori S., Robinson J. L., Moss A. J., Schwartz P. J., Towbin J. A., Vincent G. M.,
Keating M. T., Circulation, 102, 1178 -1185 (2000).

30) Nakajima T., Furukawa T., Tanaka T., Katayama Y., Nagai R., Nakamura Y., Hiraoka M., Circ. Res., 83, 415-422 (1998).

31) Shushi L., Kerem B., Goldmit M., Peretz A., Attali B., Medina A., Towbin J. A., Kurokawa J., Kass R. S., Benhorin J., Ann. Noninvasive Electrocardiol., 10, 334-341 (2005).

32) Tani Y., Miura D., Kurokawa J., Nakamura K., Ouchida M., Shimizu K., Ohe T., Furukawa T., J. Mol. Cell. Cardiol., 43, 187-196 (2007).

33) Priori S. G., Barhanin J., Hauer R. N., Haverkamp W., Jongsma H. J., Kleber A. G., McKenna W. J., Roden D. M., Rudy Y., Schwartz K., Schwartz P. J., Towbin J. A., Wilde A. M., Circulation, 99, 518-528 (1999).

34) Keating M. T., Sanguinetti M. C., Cell, 104, 569-580 (2001).

35) Schwartz P. J., Priori S. G., Spazzolini C., Moss A. J., Vincent G. M., Napolitano C., Denjoy I., Guicheney P., Breithardt G., Keating M. T., Towbin J. A. , Beggs A. H., Brink P., Wilde A. A., Toivonen L., Zareba W., Robinson J. L., Timothy K. W., Corfield V., Wattanasirichaigoon D., Corbett C., Haverkamp W., Schulze-Bahr E., Lehmann M. H., Schwartz K., Coumel P., Bloise R., Circulation, 103, 89-95 (2001).

36) Lin J. W., Wyszynski M., Madhavan R., Sealock R., Kim J. U., Sheng M., J. Neurosci., 18, 2017-2027 (1998).

37) Marx S. O., Kurokawa J., Reiken S., Motoike H., D’Armiento J., Marks A. R., Kass R. S., Science, 295, 496-499 (2002).

38) Piippo K., Swan H., Pasternack M., Chapman H., Paavonen K., Viitasalo M., Toivonen L., Kontula K., J. Am. Coll. Cardiol., 37, 562-568 (2001).

39) Paavonen K. J., Swan H., Piippo K., Hokkanen L., Laitinen P., Viitasalo M., Toivonen L., Kontula K., Heart, 86, 39- 44 (2001).

40) Bianchi L., Shen Z., Dennis A. T., Priori S. G., Napolitano C., Ronchetti E., Bryskin R., Schwartz P. J., Brown A. M., Hum. Mol. Genet., 8, 1499-1507 (1999).

41) Terrenoire C., Clancy C. E., Cormier J. W., Sampson K. J., Kass R. S., Circ. Res., 96, e25-e34 (2005).

42) Kurokawa J., Motoike H. K., Rao J., Kass R. S., Proc. Natl. Acad. Sci. U.S.A., 101, 16374-16378 (2004).

43) Chen L., Kurokawa J., Kass R. S., J. Biol. Chem., 280, 31347-31352 (2005).

44) Chen L., Kass R. S., Nat. Cell Biol., 7, 1050-1051 (2005)

45) Kurokawa J., Furukawa T., Nippon Yakurigaku Zasshi, 126, 273-279 (2005).

46) Makkar R. R., Fromm B. S., Steinman R. T., Meissner M. D., Lehmann M. H., JAMA., 270, 2590-2597 (1993).

47) Locati E. H., Zareba W., Moss A. J., Schwartz P. J., Vincent G. M., Lehmann M. H., Towbin J. A., Priori S. G., Napolitano C., Robinson J. L., Andrews M., Timothy K., Hall W. J., Circulation, 97, 2237-2244 (1998).

48) Lehmann M. H., Hardy S., Archibald D., Quart B., MacNeil D. J., Circulation, 94, 2535-2541 (1996).

49) Drici M. D., Knollmann B. C., Wang W. X., Woosley R. L., JAMA, 280, 1774-1776 (1998).

50) Fermini B., Fossa A. A., Nat. Rev. Drug Discovery, 2, 439-447 (2003).

51) Bazett H. C., J. Physiol., 53, 320-339 (1920).

52) Merri M., Benhorin J., Alberti M., Locati E., Moss A. J., Circulation, 80, 1301-1308 (1989).

53) Rautaharju P. M., Zhou S. H., Wong S., Calhoun H. P., Berenson G. S., Prineas R., Davignon A., Can. J. Cardiol., 8, 690-695 (1992).

54) Stramba-Badiale M., Spagnolo D., Bosi G., Schwartz P. J., Am. J. Cardiol., 75, 1277-1278 (1995).

55) Mangelsdorf D. J., Thummel C., Beato M., Herrlich P., Schutz G., Umesono K., Blumberg B., Kastner P., Mark M., Chambon P., Evans R. M., Cell, 83, 835-839 (1995).

56) Golden K. L., Marsh J. D., Jiang Y., Horm. Metab. Res., 36, 197-202 (2004).

57) Liu X. K., Katchman A., Whitfield B. H., Wan G., Janowski E. M., Woosley R. L., Ebert S. N., Cardiovasc. Res., 57, 28-36 (2003).

58) Simoncini T., Genazzani A. R., Eur. J. Endocrinol., 148, 281-292 (2003).

59) Furukawa T., Kurokawa J., Pharmacol. Ther., 115, 106-115 (2007).

60) Furukawa T., Bai C. X., Kaihara A., Ozaki E., Kawano T., Nakaya Y., Awais M., Sato M., Umezawa Y., Kurokawa J., Mol. Pharmacol., 70, 1916-1924 (2006).

61) Bai C. X., Kurokawa J., Tamagawa M., Nakaya H., Furukawa T., Circulation, 112, 1701-1710 (2005). 
62) Bai C. X., Takahashi K., Masumiya H., Sawanobori T., Furukawa T., Br. J. Pharmacol., 142, 567-575 (2004).

63) Bai C. X., Namekata I., Kurokawa J., Tanaka H., Shigenobu K., Furukawa T., Circ. Res., 96, 64-72 (2005)

64) Campbell D. L., Stamler J. S., Strauss H. C., J. Gen. Physiol., 108, $277-293$ (1996).
65) Hare J. M., Stamler J. S., J. Clin. Invest., 115, 509-517 (2005).

66) Collins K. K., Van Hare G. F., Curr. Opin. Pediatr., 18, 497-502 (2006).

67) Kass R. S., Kurokawa J., Marx S. O., Marks A. R., Trends Cardiovasc. Med., 13, 52-56 (2003). 